\title{
MORFOMETRIA DO RELEVO NA BACIA DO RIO DA CA- CHOEIRA NO CONTEXTO DO PLANO DE MANEJO DA FLORESTA NACIONAL DE PASSA QUATRO (MG)
}

\section{Relief morphometry in the Cachoeira river basin in the mana- gement plan of Floresta Nacional de Passa Quatro (MG)}

\author{
Roberto MARQUES NETO ${ }^{1}$ \\ Fábio da Silva GONÇALVES ${ }^{2}$ \\ Ramiris Moraes da CONCEIÇÃO ${ }^{2}$ \\ Fábio da Silva FERNANDES ${ }^{2}$ \\ José Ricardo Machado VIEIRA ${ }^{2}$
}

Nemo Gomes SIMAS ${ }^{2}$

\begin{abstract}
RESUMO
As Unidades de Conservação têm um papel fundamental no processo de proteção ambiental e conservação dos recursos naturais. No contexto do plano de manejo de Unidades de Conservação, as formas e padrões morfométricos do relevo e os processos geomorfológicos tem grande importância, tanto pelo fato de constituírem o substrato físico sobre o qual se desenvolvem as atividades humanas como por responderem às alterações provocadas por tais atividades. A análise do relevo é uma das várias formas de se entender a dinâmica espacial. Desse modo, a cartografia geomorfológica torna-se instrumental importante para um plano adequado. Este artigo mostra aspectos morfométricos do relevo (declividade, dissecação vertical e dissecação horizontal) na bacia do rio da Cachoeira, área da Floresta Nacional de Passa Quatro (MG), sul do estado de Minas Gerais, como subsídio ao plano de manejo da unidade de conservação e gestão integrada da área.
\end{abstract}

Palavras-chave: dissecação vertical; dissecação horizontal; plano de manejo; dinâmica erosiva.

\begin{abstract}
The Units of Conservation have a fundamental paper in the process of environmental protection and conservation of the natural resources. In the context of management plan of Units of Conservation, the forms and morphometric patterns of the relief and geomorphological process have got great importance by the fact that they form the physical substratum on wich develop the human activities, answering the alterations provoked by such activities. The analysis of relief is one of the some forms of if understanding the spatial dynamics. In this way, the geomorphological cartography comes as a vital instrument for a appropriate plan. This article shows morphometric aspects of the relief (declivity, vertical dissection and horizontal dissection) in the basin of the Rio da Cachoeira (Waterfall River), area of the Floresta Nacional de Passa Quatro (MG), south of Minas Gerais state, as subsidy to the management plan of the Unity of Conservation and the integrated management of the area.
\end{abstract}

Keywords: vertical dissection; horizontal dissection; management plan; erosive dynamics. 


\section{INTRODUÇÃO}

O presente diagnóstico de cunho geomorfológico se insere no conjunto de atividades realizadas para o plano de manejo da Floresta Nacional de Passa Quatro (FLONA), levado a efeito por coordenação do IBAMA, que tem unidade no referido município, localizado na Serra da Mantiqueira, sul de Minas Gerais.

As bases buscadas pelo plano de manejo no âmbito das geociências abrangeram o mapeamento geológico e geomorfológico da área da FLONA, uma apreciação sumária da dinâmica erosiva vigente e a elaboração de propostas e sugestões para o plano à luz dos resultados obtidos, além do levantamento pedológico efetivado por equipe incumbida dessa tarefa.

$\mathrm{Na}$ oportunidade que agora sobrevém, toma-se por intuito comunicar resultados referentes ao diagnóstico de ordem geomorfológica, que se ocupou da mensuração de aspectos morfométricos do relevo, os quais: declividade, dissecação horizontal e dissecação vertical.

Todos elementos morfométricos analisados são de grande valia na interpretação e ponderação sobre os processos erosivos que marcam a fisiologia da paisagem e que interessam para a elaboração do plano, devendo constar em seu relatório final. O conjunto de atividades dispensadas ao plano de manejo, onde se insere o presente trabalho, também comportou a edição da carta geomorfológica acompanhada de descrição das unidades discernidas, além do mapeamento geológico com caracterização dos litotipos encontrados. Os resultados aqui apresentados se referem apenas àqueles obtidos por meio da análise morfométrica do relevo, colocando em tela o quadro morfogenético como condicionante aos programas de conservação, manejo e recuperação a serem implementados.

\section{MATERIAIS UTILIZADOS E PROCEDIMENTOS ADO- TADOS}

As análises morfométricas foram executadas sobre a carta topográfica (Folha Passa Quatro, SF-23-ZA-I-3) em escala de $1 / 50000$, bases cartográficas para a espacialização da declividade e dissecação do relevo.
A declividade do terreno foi mensurada segundo intervalos de classe e projetadas no espaço da FLONA e seu entorno por meio do uso do ábaco graduado (DE BIASI, 1992), acatando os aprimoramentos propostos por Sanchez (1993).

Tal proposta consiste na construção de um ábaco ou diapasão tomando como referência a maior e menor distância medida entre as curvas de nível, que indicarão, respectivamente, a máxima e a mínima declividade do terreno, a serem representadas em porcentagem, entre as quais são distribuídos os demais intervalos de classe.

A mensuração da dissecação horizontal do relevo (distância horizontal entre os talvegues e suas respectivas linhas de cumeada) seguiu as orientações de Spiridonov (1981) complementada pelas adaptações de Mauro et al. (1991), que consiste na confecção de um ábaco graduado para ser utilizado como elemento facilitador na apreciação desse aspecto morfométrico. Essa técnica tem como princípio básico o enriquecimento da drenagem nos setores onde as curvas-de-nível orientam a convexidade para montante (indicando drenagem ativa), sendo posteriormente delimitadas todas as sub-bacias que partilham do sistema hidrográfico estudado, para deslizamento do ábaco entre o canal fluvial e a linha divisória local.

Para a mensuração da dissecação vertical, que é a distância vertical entre o talvegue e o divisor (o que reflete a profundidade de entalhamento do canal) foi adotada a proposta de Hubp (1988), de mais fácil aplicação em áreas de topografia íngreme e densamente dissecada. Conforme essa técnica, as bacias hidrográficas com as sub-bacias internas individualizadas são sobrepostas em papel milimetrado estruturado em células quadráticas com tamanho de $1 \mathrm{~cm} \times 1 \mathrm{~cm}$. A amplitude altimétrica medida dentro de cada célula foi anotada em um ponto no centro do quadrado, e os valores obtidos unidos por interpolação linear para o agrupamento dos trechos de dissecação vertical semelhante e estabelecimento de intervalo adequado para as classes.

A mensuração de aspectos morfométricos do relevo como subsídio a análise geomorfológica para o plano de manejo partilha integradamente de um conjunto sistemático de procedimentos que foram acionados para a execução da pesquisa em sua totalidade, conforme segue esquematizado na Figura 1. 
NETO, R. M. et al. Morfometria do relevo na bacia do rio da cachoeira...

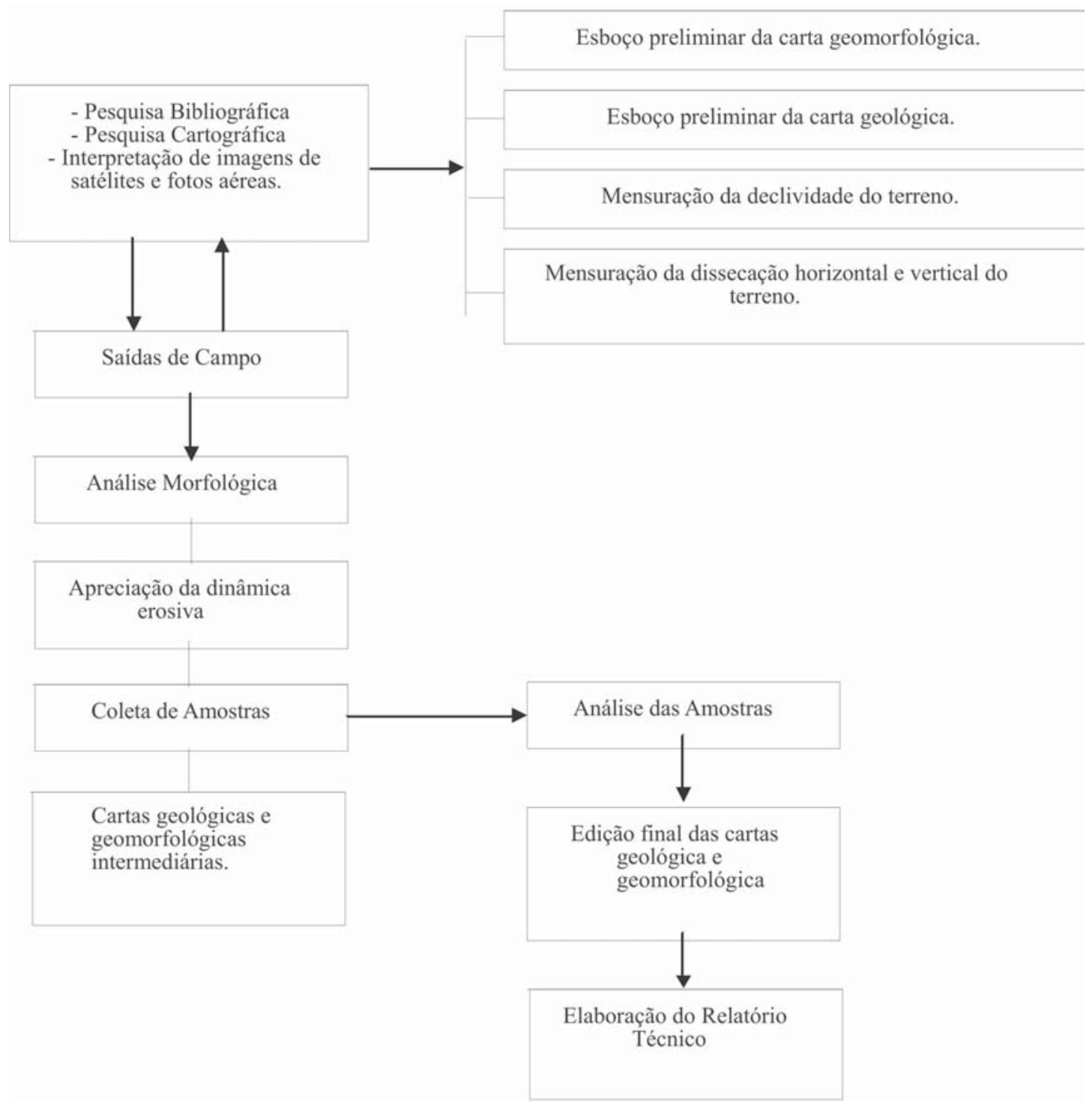

FIGURA 1 - DIAGRAMA ESQUEMÁTICO DOS PROCEDIMENTOS ADOTADOS

\section{A ÁREA DE ESTUDO}

No perímetro da FLONA, contido em 335 ha (Figura 2), o arcabouço geológico é representado por rochas intrusivas alcalinas (nefelina-sienitos) cretáceas e gnaisses bandados pré-cambrianos agrupados no Complexo Paraíba do Sul (PROJETO RADAMBRASIL, 1983); (HASUI; OLIVEIRA, 1984). Há tempos depósitos bauxíticos geneticamente vinculados a rochas alcalinas foram registrados na parte sudoeste da floresta (HEISEKE; LAMAS, 1974), (SÍGOLO, 1997).

As intrusões alcalinas configuram batólito que impõem contato abrupto com os gnaisses-granitos da Serra da Mantiqueira. A intrusão desses corpos plutô- nicos está relacionada à reativação tectônica instalada por efeito da separação das placas Sul-Americana e Africana e abertura do Atlântico-Sul, fenômeno designado Reativação Wealdeniana (ALMEIDA, 1967) ou evento Sul-Atlântico (SCHOBBENHAUS et al. 1984).

A FLONA está localizada na Serra da Mantiqueira, unidade morfoestrutural circunscrita no Planalto Atlântico, que pode ser compartimentado, segundo a diversidade litoestrutrual e morfológica, nas seguintes unidades: Planalto da Bocaina, Planalto de Paraitinga, Médio Vale do Paraíba do Sul, Serra da Mantiqueira, Planalto de Campos do Jordão e Planalto Paulistano (ALMEIDA, 1964). 
NETO, R. M. et al. Morfometria do relevo na bacia do rio da cachoeira...

Os relatórios do Projeto RADAMBRASIL (1983) inserem a área na chamada faixa de dobramentos remobilizados, situando a área de estudo no que designou como Mantiqueira Meridional, subdividida em Planalto de Campos do Jordão e Planalto do Itatiaia, onde se localiza o município de Passa-Quatro e o perímetro da FLONA. Para a área do Planalto do Itatiaia, Modenesi (1992) nota o contraste entre o relevo caracterizado por morros íngremes e picos rochosos das bordas (Pedra do Couto, $2.682 \mathrm{~m}$, Patreleiras, $2.515 \mathrm{~m}$ ) e da parte central (Agulhas Negras, $2.787 \mathrm{~m}$, Pedra do Altar, 2.661m) com setores planos ocupados por várzeas turfosas na planície de inundação de algumas drenagens, como o ribeirão das Flores e os rios Aiuruoca e Preto. A autora também chama a atenção para o forte controle estrutural refletido nos aspectos gerais do relevo, com falhas circulares contemporâneas à intrusão alcalina onde se ajusta uma drenagem radial expressa no alto curso dos rios Aiuruoca, Preto, Campo Belo e Itatiaia.

O padrão tectono-estrutural regional obedece a uma orientação geral SW-NE, condizente aos principais alinhamentos dos cinturões de cisalhamento do sudeste brasileiro, estando a área próxima dos cinturões de cisalhamento de Wenceslau Brás e Passa Quatro.

Na FLONA, a cobertura pedológica associada ao relevo amorreado embasado por gnaisses se refere a Argissolo Vermelho Amarelo na parte NE, e para o qual é registrada ocorrência conspícua em Passa Quatro, com registro de Neossolo Litólico nos setores mais declivosos e de consideráveis extensões revestidas por Cambissolos Háplicos e típicos. Na parte central da floresta uma ruptura de declive individualiza setor com declividades moderadas que permitiram o desenvolvimento de Latossolo Vermelho Amarelo, que aparece em algumas trincheiras com o horizonte $A$ enterrado indicando severo descarnamento superficial durante o Pleistoceno.

O espaço interno da FLONA contém apenas 38 ha de mata latifoliada subcaducifólia, com destacada ocorrência de candeias, e 38 ha de mata ombrófila mista com presença de araucárias (Araucaria angustifolia). Ademais, o uso do solo é orientado à prática do reflorestamento, destacadamente Pinus elliotti (102 ha) e também araucárias plantadas (109 ha). O entorno imediato, à montante da área da floresta, apresenta considerável cobertura de mata primitiva preservada nas encostas mais elevadas, que, a partir de cotas situadas em torno de 1800 metros, é substituída pelos campos de altitude. A vegetação rasteira das altitudes povoa, na bacia do rio da Cachoeira e em outras bacias de drenagem dispostas paralelamente com as cabeceiras no maciço alcalino, setores de vertentes altamente íngremes, intercalandose com magníficos afloramentos.

O tipo climático vigente se refere ao clima tropical de altitude, com temperaturas moderadas pela altitude em relação ao clima tropical típico.

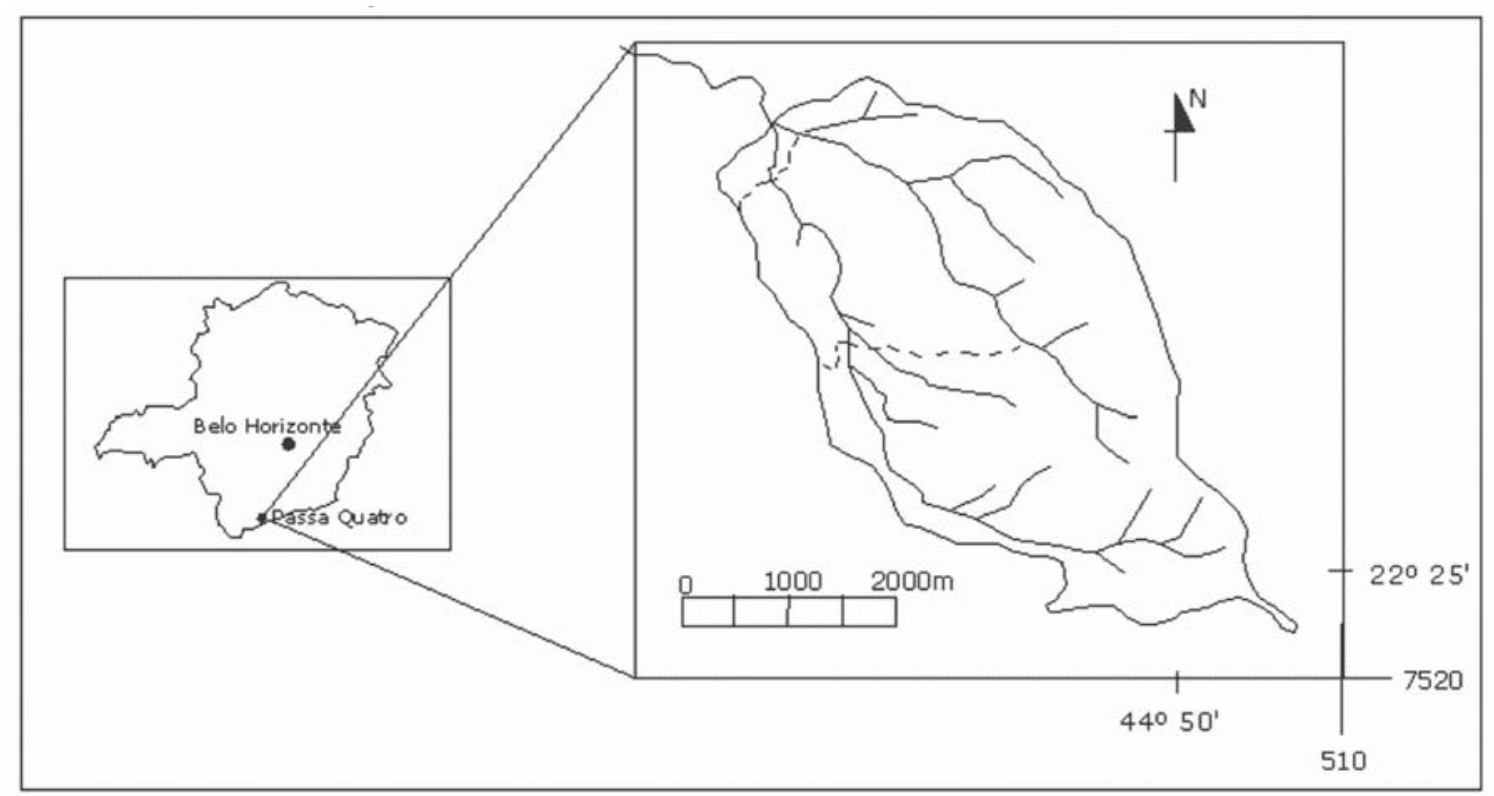

FIGURA 2 - LOCALIZAÇÃO DA ÁREA DE ESTUDO COM O PERÍMETRO DA FLONA EM LINHA PONTILHADA NO ESPAÇO INTERNO DA MÉDIA-ALTA BACIA DO RIO DA CACHOEIRA 


\section{A MORFOMETRIA DO RELEVO}

\section{A DECLIVIDADE DO TERRENO}

A análise da declividade por meio da edição da carta clinográfica feita para a FLONA e para a áreatampão situada à montante na bacia hidrográfica em que se insere (Figura 1 ) estimou os seguintes intervalos de classe:

$$
\begin{gathered}
<20 \% \\
20-30 \% \\
30-40 \% \\
>40 \%
\end{gathered}
$$

Em linhas gerais a área é caracterizada por altas declividades, exceção feita para os terraços que se desenvolvem no extremo norte da FLONA nas imediações da foz do rio da Cachoeira em relevo de planície e para trecho de relevo ondulado que marca parte da linha divisória entre o rio da Cachoeira e o ribeirão Carlos Tibúrcio, onde as declividades moderadas se rebaixam aquém de $20 \%$ e permite o desenvolvimento de Latossolo Vermelho Amarelo.
Os declives mais acentuados aparecem na parte SE da FLONA, nos primeiros degraus do maciço alcalino que faz a marcação em ruptura de declive entre esse compartimento geomorfológico e a área de relevo amorreado. A margem esquerda do rio da Cachoeira também comporta declividades consideráveis que oscilam nas duas classes superiores, que por sinal são aquelas que predominam dentro da floresta.

Os altos valores de declividade também são predominantes em toda a alta bacia do rio da Cachoeira, onde as encostas são excessivamente íngremes, conferindo alta energia ao relevo do qual a FLONA faz parte. O predomínio do intervalo de classe extremo é verificado com maior firmeza na margem direita do ribeirão Carlos Tibúrcio, posicionada além dos limites da floresta, mas cuja conexão determina a entrada de material em seu espaço interno, sobretudo nos eventos espasmódicos que ocorrem nas estações chuvosas e que são responsáveis por transbordamentos não-habituais.

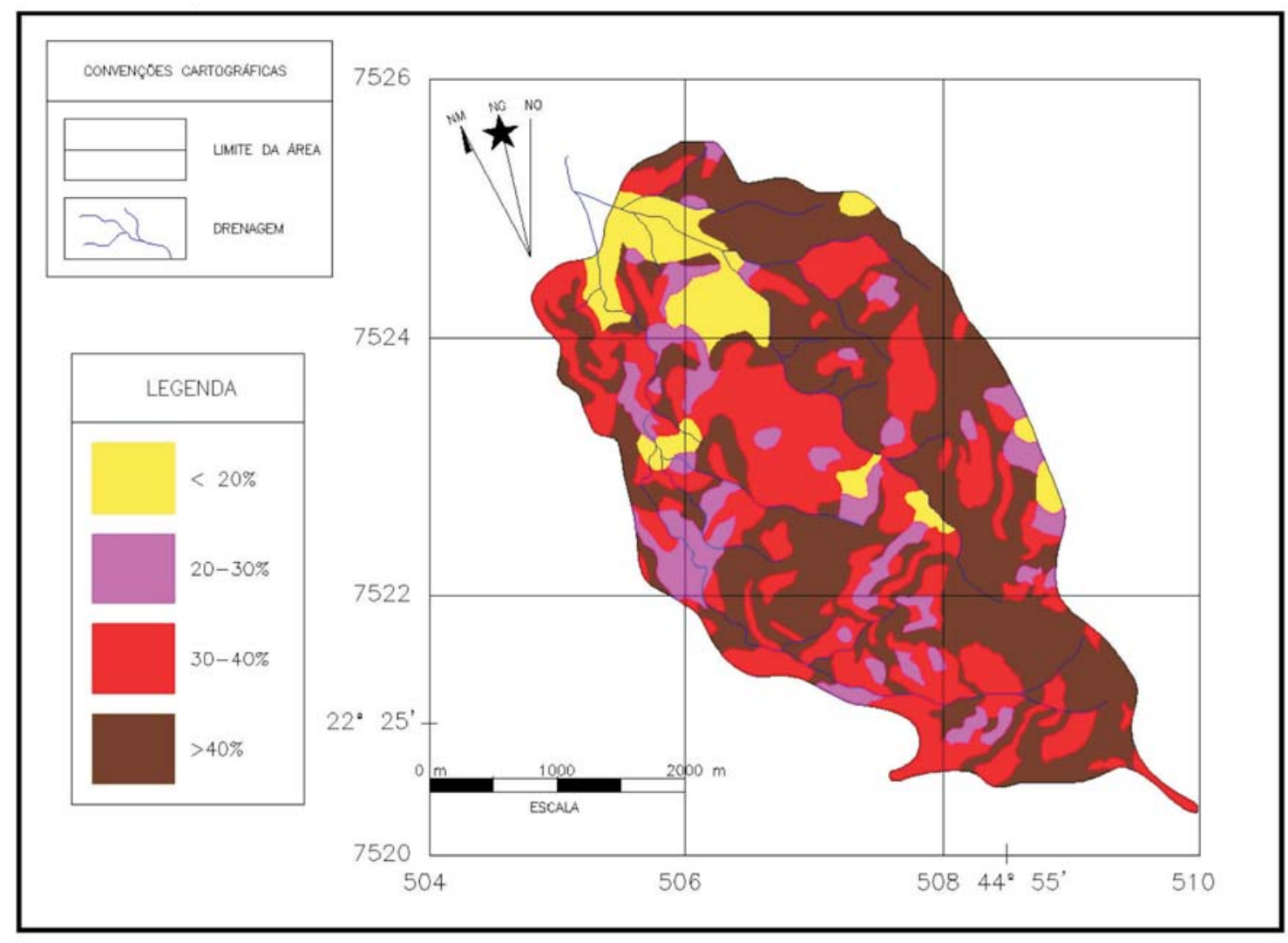

FIGURA 3 - CARTA CLINOGRÁFICA DA MÉDIA-ALTA BACIA DO RIO DA CACHOEIRA (PASSA QUATRO, MG) 


\section{A DISSECAÇÃO DO RELEVO}

A mensuração da dissecação horizontal do relevo (Figura 2) se deu com base nos intervalos de classe apresentados no Quadro 2, tendo sido considerado o valor mínimo de 50 metros, menor extensão passível de representação na escala trabalhada (1/50000):

\begin{tabular}{|c|c|}
\hline CLASSE DE DISSECAÇÃO & DISTÂNCIA NA CARTA \\
\hline$<50$ metros & $<1 \mathrm{~mm}$ \\
\hline $50-100$ metros & $1-2 \mathrm{~mm}$ \\
\hline $100-200$ metros & $2-4 \mathrm{~mm}$ \\
\hline $200-400$ metros & $4-8 \mathrm{~mm}$ \\
\hline$>400$ metros & $>8 \mathrm{~mm}$ \\
\hline
\end{tabular}

QUADRO 1 - CLASSES DE DISSECAÇÃO HORIZONTAL OBTIDAS
A incidência de canais fluviais perenes se concentra nos eixos da drenagem do rio da Cachoeira e do ribeirão Carlos Tibúrcio. Extensa vertente convexa a retilínea marca a linha divisória entre os dois cursos d'água, onde os valores de dissecação horizontal são baixos, padronizando-se nas classes superiores. Tal comportamento reflete a estrutura maciça e de baixo fraturamento das intrusivas alcalinas, com menos zonas de fraqueza a serem exploradas pela drenagem, controlando a afluência do ribeirão Carlos Tibúrcio no rio da Cachoeira sob baixa dissecação por tributários. A erosão no sopé do maciço alcalino por desgaste das vertentes é responsável por aplainamento e alargamento das baixadas e preenchimento sedimentar.

Não são verificadas maiores restrições do ponto de vista da dissecação horizontal, exceção feita a pontos próximos às confluências onde o solapamento das margens é mais severo e as linhas erosivas se encontram mais aproximadas.

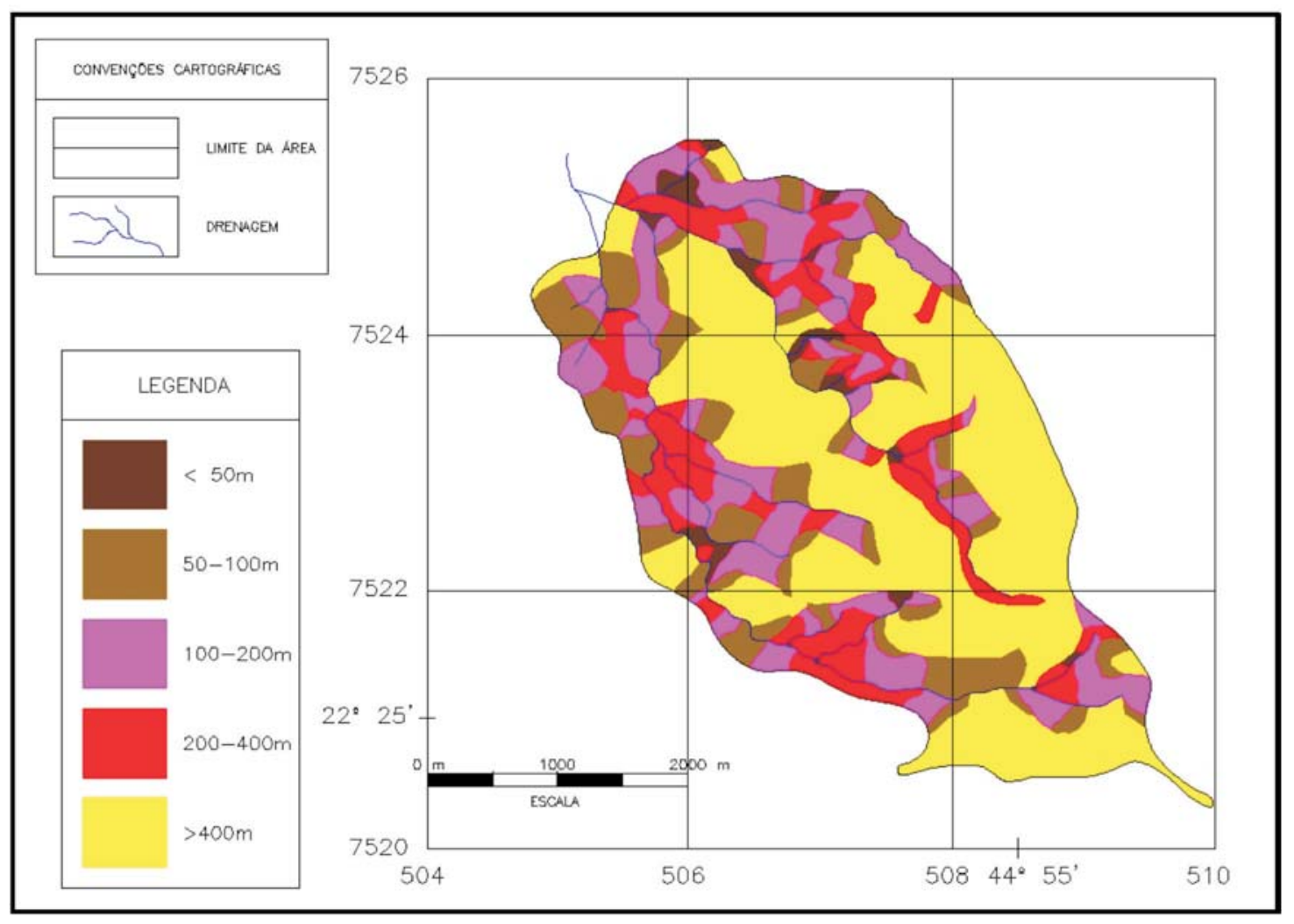

FIGURA 4 - CARTA DE DISSECAÇÃO HORIZONTAL DO RELEVO DA MÉDIA-ALTA BACIA DO RIO DA CACHOEIRA (PASSA QUATRO, MG) 
Para a dissecação vertical foram obtidos os seguintes intervalos de classe:

$$
\begin{gathered}
<80 \text { metros } \\
80-120 \text { metros } \\
120-160 \text { metros } \\
160-200 \text { metros } \\
200-240 \text { metros } \\
240-280 \text { metros } \\
280-320 \text { metros } \\
>320 \text { metros }
\end{gathered}
$$

$\mathrm{Na}$ a área de estudo, a dissecação vertical foi considerada mais preponderante que a dissecação horizontal no desenvolvimento de processos geomórficos. A drenagem se caracteriza por forte encaixamento em fraturas sob forte controle tectônico, fator que impõe uma elevada energia gravitacional a ser trabalhada em fortes amplitudes altimétricas entre topo e fundo de vale. Instala-se em função da pronunciada dissecação vertical uma alta suscetibilidade de remoção e transporte de material ao longo das vertentes íngremes que estabelecem contatos com os canais fluviais em desníveis acentuados.
A dissecação vertical na área de estudo sofre diferenciações por efeito da variação na litologia. Na parte norte, onde o aflora o embasamento pré-cambriano em litologia gnáissica e o relevo é rebaixado pela erosão diferencial, os valores de dissecação vertical se agrupam nas três classes inferiores para assumirem condições moderadas em relação a esse parâmetro. $O$ divisor das águas do rio da Cachoeira e do ribeirão Carlos Tibúrcio encontra-se demasiadamente rebaixado perto da junção desses canais fluviais, de maneira que ambos os cursos d'água encontram-se, nesse trecho, no mesmo nível, o que assinala iminência de captura.

A profundidade de entalhamento aumenta à medida que se adentra ao maciço alcalino, assumindo valores máximos no extremo sudeste da bacia do rio da Cachoeira. Desse modo, toda a área à montante da FLONAé caracterizada por fortes índices de dissecação vertical (Figura 5), o que assegura uma forte contribuição de carga detrítica para o espaço interno da floresta por meio das vertentes e dos canais fluviais, processo que pode ser realçado por força de chuvas fortes e concentradas.

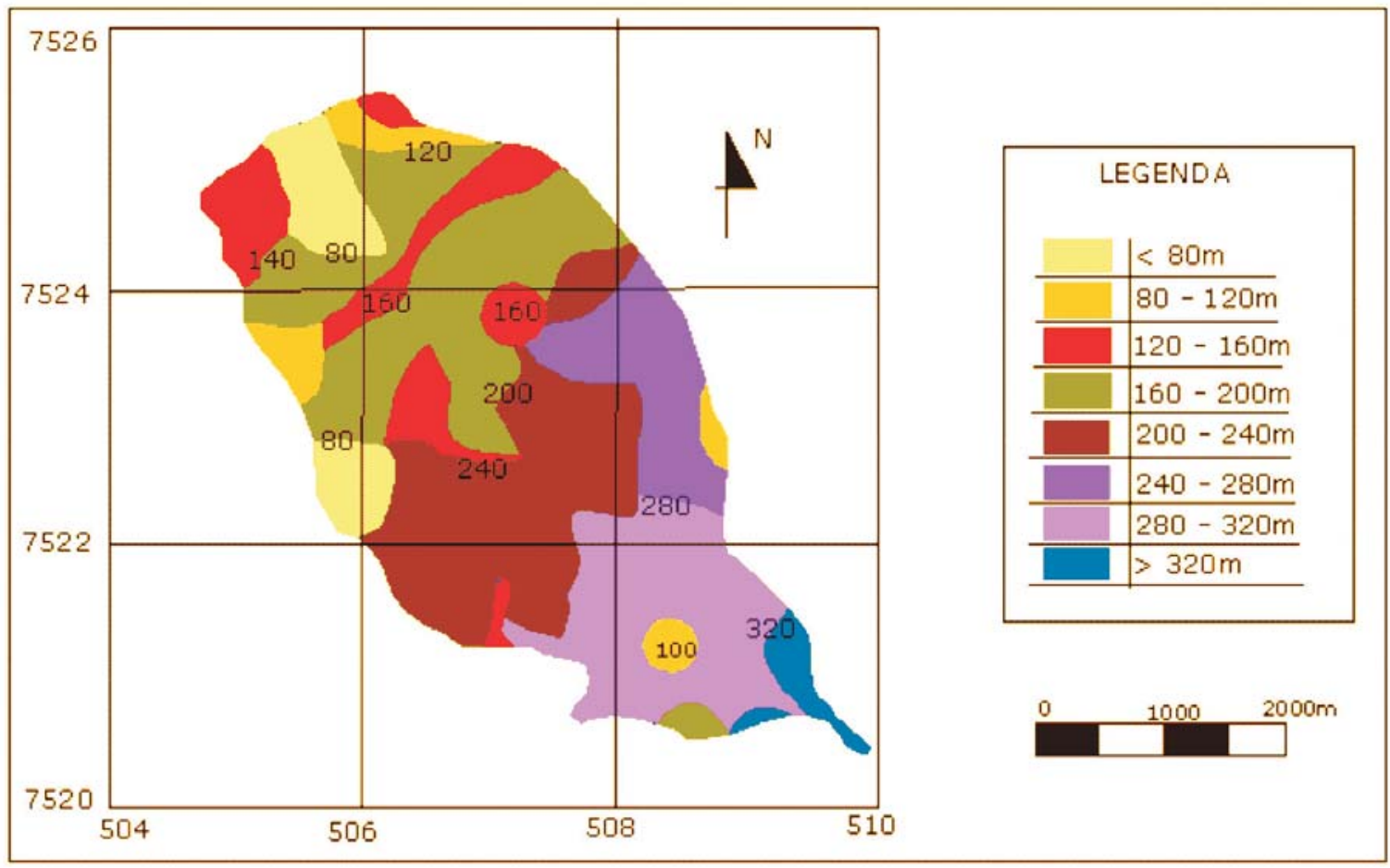

FIGURA 5 - CARTA DE DISSECAÇÃO VERTICAL DO RELEVO DA MÉDIA-ALTA BACIA DO RIO DA CACHOEIRA (PASSA-QUATRO, MG) 
NETO, R. M. et al. Morfometria do relevo na bacia do rio da cachoeira...

\section{A MORFOMETRIA DO RELEVO COMO CONDICIO- NANTE PARA O PLANO DE MANEJO}

O espaço interno da FLONA é caracterizado por um relevo de energia elevada, com declives consideráveis e dissecação, sobretudo no que concerne ao entalhe vertical, significativamente densa, o que confere para o terreno em apreço uma alta susceptibilidade potencial à erosão, propriedade que pode ser estendida ao quadro geomorfológico referente às frentes escarpadas, taludes e morros declivosos e de vertentes curtas da Serra da Mantiqueira. Dessa forma, a área de estudo é exemplarmente representativa de um quadro geomorfológico regional marcado por acentuada fragilidade potencial.

A manifestação erosiva que predomina dentro da FLONA é a erosão laminar, levada a efeito pelo escoamento em lençol, que é tanto mais eficiente quanto maior o declive do terreno, sem desconsiderar a erosão por salpicamento (splash erosion), etapa inicial de desestabilização dos agregados do solo para posterior remoção pelo escoamento superficial e cuja significância varia conforme a cobertura vegetal e sua respectiva eficiência de interceptação das gotas de chuva.

A intensidade desses processos morfogenéticos no espaço atualmente ocupado pela FLONA deve ter sido maior em tempos anteriores ao reflorestamento. São registrados no espaço interno da floresta vastos setores de solo raso, predominantemente Cambissolos, com bolsões localizados de Neossolo Litólico, onde o próprio reflorestamento é dificultado ou inviabilizado, o que indica perda recente do manto pedológico por erosão hídrica na forma de escoamento em lençol.

Nas vertentes íngremes da margem esquerda do rio da Cachoeira o relevo padronizado em morros suporta intercalação de pinus com mata nativa, o que instiga a suposição da existência certa de diferentes índices erosivos conforme a cobertura. É seguro afirmar que nos setores cobertos pela mata latifoliada a perda de solo por erosão laminar é menor, em virtude da maior interceptação das águas pluviais pelo sistema foliar da vegetação arbórea e que também se processa no nível do sub-bosque, assegurando uma atenuação da energia cinética das gotas de chuva e de seu impacto quando atinge o solo. Os andares arbustivos e herbáceos também contribuem de maneira decisiva na difusão do escoamento superficial, evitando a concentração dos fluxos hídricos e distribuindo mais eqüitativamente a energia erosiva da água no solo à medida que confi- guram obstáculos que divergem o escoamento hídrico em variadas direções.

O fenômeno da interceptação da chuva pela vegetação é bem menos eficiente onde a cobertura é de pinus. A conformação das copas não viabiliza uma retenção eficiente do input natural que vem da atmosfera, e, conseqüentemente, um maior volume d'água atinge diretamente o solo com maior erosividade. Esse fator, somado ao fato das declividades serem consideráveis no setor, determina um maior rigor da erosão laminar, registrado em solos extremamente rasos. Com o subbosque empobrecido nas áreas de pinus o atrito imposto à água de escoamento superficial também é menor, o que é componente favorável para uma retirada mais competente de lâminas das camadas superiores do solo pelo fluxo hídrico de superfície.

Espaços de declividade moderada a forte na parte leste da FLONA correspondem a reflorestamentos de araucárias (Araucaria angustifolia). Do ponto de vista da estabilidade morfodinâmica, essa prática de reflorestamento situa-se em posição intermediária entre a mata nativa e o reflorestamento de pinus, tanto no que concerne interceptação das águas pluviais como no tocante ao efeito difusor processado pelos troncos e estratos inferiores.

Todo o setor posicionado à montante da FLONAé de onde provém (com exceção das águas que atingem o substrato advindas diretamente do nível da atmosfera) toda a descarga de matéria e energia para a área da floresta. O material absorvido pela FLONA, e que esta armazena, trabalha, transporta e converte em output, tem como fonte as vertentes da alta bacia do rio da Cachoeira, e, em condições extremas do rigor climático tropical atlântico, pode receber descargas oriundas da margem direita do ribeirão Carlos Tibúrcio, com alterações na morfologia fluvial por efeito de transbordamentos esporádicos. Os altos valores que a dissecação vertical assume na alta bacia do rio da Cachoeira agravam o quadro descrito à medida que confere elevada energia gravitacional para movimentação de materiais a serem depositados nas partes baixas.

Episódios de anomalia climática podem alterar significativamente a paisagem em um intervalo de tempo demasiadamente reduzido, modificando a morfologia e a direção e natureza dos fluxos de matéria e energia acompanhada de reorganização erosiva do sistema.

Dentro da FLONA modificações abruptas no regime erosivo e sedimentar da rede de drenagem se deram 
por efeito das chuvas fortes de janeiro de 2000, que desencadearam processos erosivos de monta nas altas vertentes da Serra da Mantiqueira. Conti (2001) informa que, durante esse evento, o município de Passa-Quatro concentrou, nos quatro primeiros dias do ano, 600,6 mm de chuvas (322,7 apenas no dia 3$)$, tendo sido um dos municípios mais castigados, com desestabilização de encostas, assoreamento de cursos d'água, danificação e destruição de residências com fileiras de desabrigados e arrasamento do sistema de abastecimento de água. A descarga violentamente depositada durante as fortes chuvas nos compartimentos rebaixados alterou drasticamente a natureza da contribuição de material nos diversos subsistemas, o que determinou modificações severas na morfologia dos canais fluviais e planícies de inundação.

Em seu baixo curso, o ribeirão Carlos Tibúrcio desviou a direção de escoamento e escavou rapidamente um novo leito com acentuada energia erosiva concentrada em descarga anômala, e pelo qual divaga em pequena extensão até se ajeitar novamente ao seu leito original logo à jusante.

A frente de escoamento proveniente dos terrenos mais elevados escavou significativamente alguns pontos onde a concentração foi favorecida pela microtopografia, atingindo o nível freático e expondo novas nascentes em olhos d'água que atingem mais de 1 metro de profundidade.

A planície de inundação no baixo curso do ribeirão Carlos Tibúrcio foi alargada em aproximadamente 15 metros e coberta por depósitos arenosos com cerca de $18 \mathrm{~cm}$ de espessura sobrejacentes a um pavimento de seixos e matacões que foram trazidos em correntes que exerceram forte abrasão e modificaram a geometria do canal fluvial e a arquitetura sedimentar.

Os efeitos erosivos decorrentes das altas chuvas de janeiro de 2000 também se encontram registrados nas vertentes conectadas ao espaço interno da FLO$\mathrm{NA}$, onde marcas de deslizamento e fluxo concentrado persistem na morfologia atual da paisagem como testemunho da desestabilização das encostas e conseqüente modificação nos canais fluviais e relevo associado para o qual os sedimentos foram carreados.

Retomando em síntese o exposto, uma avaliação preliminar da dinâmica erosiva na FLONA informa o predomínio claro da erosão normal (laminar e por salpicamento), processada de maneira lenta, com distúrbios episódicos que orientam a geomorfogênese nos termos da erosão acelerada, e que são ocasionados por azares climáticos que alteram bruscamente a relativa e discutível uniformidade do regime erosivo e deposicional. O último evento espasmódico que atuou em desconformidade com o padrão morfogenético vigente foi o de janeiro de 2000, o que permite aventar que outros episódios dessa magnitude afetaram os processos normais em tempos históricos e virão a afetar em outras ocasiões.

\section{CONSIDERAÇÕES FINAIS}

A apreciação de parâmetros morfométricos do relevo é de grande valia para a averiguação do quadro morfogenético e auxilia de forma objetiva o entendimento da dinâmica erosiva de uma área, oferecendo informações importantes no estabelecimento de diretrizes para o uso do solo. A agilidade na obtenção da declividade e dissecação do terreno converte estas técnicas em saídas plausíveis para apreciações acerca da fragilidade real e potencial da paisagem, tendo sido demonstrado importância para o diagnóstico geomorfológico levado a efeito para compor o conjunto de dados referentes ao plano de manejo.

A manutenção da estabilidade morfodinâmica dentro da FLONA está na dependência da conservação da totalidade da bacia hidrográfica do rio da Cachoeira à montante da floresta. As últimas manifestações climáticas de maior força revelam cabalmente a elevada energia do relevo nesse espaço de alta instabilidade potencial, dotado de vertentes íngremes e significativa profundidade de dissecação, o que pode desencadear processos de movimentos de massa mesmo com a presença da cobertura vegetal.

Qualquer tipo de uso do solo que não vise a conservação não pode ser sugerido como adequado para a área posicionada à montante da FLONA, admitindose também a recuperação de áreas detectadas como degradadas, o que se justifica não apenas em função do quadro topográfico desafiador, com extensivos trechos com declividades acentuadas, mas também pelo interesse biológico que se deposita nos remanescentes de mata atlântica e os estoques florísticos e faunísticos que ali se encontram. Além da pesquisa e atividades como coleta de sementes, o máximo que a área permite é a atividade turística planejada, com controle de fluxos e monitoramento constante do espaço para detectar possíveis efeitos negativos no quadro ambiental. 
NETO, R. M. et al. Morfometria do relevo na bacia do rio da cachoeira...

\section{REFERÊNCIAS}

ALMEIDA, F. F. M. Fundamentos geológicos do relevo paulista. Boletim IGG, n. 41, p. 169-263, 1964.

. Origem e evolução da Plataforma Brasileira. Rio de Janeiro: DNPM/DGM, 1967, 36p.

CONTI, J. B. Resgatando a "fisiologia da paisagem". Revista do Departamento de Geografia, São Paulo, n. 14, p. 59-68, 2001.

DE BIASI, M. A carta clinográfica: os métodos de representação e sua confecção. Revista do Departamento de Geografia. São Paulo, n. 6, p. 45-61, 1992.

HASUI, Y.; OLIVEIRA, M. A. F. Província Mantiqueira: setor central. In: ALMEIDA, F. F. M. O Pré-Cambriano do Brasil. São Paulo: Edgard Blücher, 1984.

HEISEKE, D. R.; LAMAS, J. M. Inventário e manejo da FLONA de Passa Quatro em Minas Gerais. Brasil Florestal, v. 5, n. 18, 1974.

HUBP, J. I. L. Elementos de geomorfologia aplicada. México: Universidad Nacional Autonoma de México, D. F. 1988. $128 p$.
MAURO, C. A. et al. Contribuição ao planejamento ambiental de Cosmópolis - SP - BR. ENCUENTRO DE GEÓGRAFOS DE AMÉRICA LATINA. Toluca: UAEM, v. 4, p. 391-419, 1991.

MINISTÉRIO DAS MINAS E ENERGIA. Projeto RADAMBRASIL, Folha SF-23 Vitória/Rio de Janeiro, Rio de Janeiro, 1983.

MODENESI, M. C. Depósitos de vertente e evolução quaternária do Planalto do Itatiaia. Revista do Instituto Geológico, São Paulo, USP, v. 13, n. 1, 1992, p. 31-46.

SANCHEZ, M. C. À propósito das cartas de declividade. In: SIMPÓSIO BRASILEIRO DE GEOGRAFIA FÍSICA APLICADA. 5, 1993, Anais... São Paulo. FFLCH: São Paulo, 1993.

SCHOBBENHAUS, C.; CAMPOS, D. A.; DERZE, G. R.; ASMUS, H. E. Geologia do Brasil. Brasília: MME/DNPM, 1984. 501p.

SíGOLO, J. B. Os depósitos de talude de Passa Quatro. In: SIMPÓSIO DE GEOLOGIA DO SUDESTE 5, 1997. Anais... Penedo, RJ, v. 1, p. 1-8.

SPIRIDONOV, A. I. Princípios de la metodologia de las investigaciones de campo y el mapeo geomorfológico. Havana: Universidad de la Habana, 1981. 